\title{
MODERNIZATION OF THE HYDROSTATIC DRIVE OF LOWER GATE LOCKS IN WATERWORKS GABCIKOVO
}

\author{
Ing. Karol STRAČÁR \\ Institute of process and fluid engineering, Faculty of mechanical engineering, STU Bratislava, \\ karol.stracar@stuba.sk
}

\begin{abstract}
This paper deals with analysis of the combined load on hydraulic cylinder. Based on measurements of the parameters of the hydraulic cylinder and accurate calculations conclusions were drawn. Measurements were made on the lower hydrostatic drive gate locks at the waterworks Gabcikovo. Method of fixation of the hydraulic cylinder creates added bending torques which causes deformation of piston rod. The results are an effort to find relationship between dimensions, loading and safe operation.
\end{abstract}

Keywords: hydraulic cylinder, lock chamber, static behaviours, safety load

\section{INTRODUCTION}

This paper deals with the problem of determining inputs for the reconstruction of the hydrostatic drive of lower gate locks, on the basis of measured values, computation and results of the mechanism. The experiments were done on the hydraulic system of lower gate locks left chamber, right gate.

\section{PROCEDURE}

According to the analysis of the results from hydraulic measurement, performed on the driving part of the right gate in the left water chamber and in cooperation with operator of the mechanism, were given these inputs:

Max. force in gate opening (arrest close to the wall of chamber) :

$30.10^{4} \mathrm{~N}$

Max. force in gate closure (arrest on the threshold of the chamber):

Emergency control (max. force)

Max. velocity while opening (ejection of the piston rod):

Range of the operating temperatures:

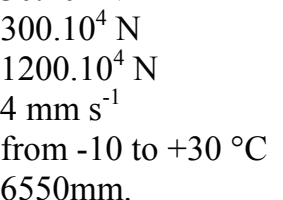
Kinematics of the mechanism and the stroke of the cylinder remain default at $6550 \mathrm{~mm}$.

The engine room of the hydraulic system is situated in the original place. In the software Matlab, a computational program was developed for the purposes of determining buckling resistance and safety of the piston rod of the horizontally situated hydraulic cylinder (HV) and the various possibilities of piston and piston rod diameters.

\section{MEASURED VALUES AND ITS ANALYSIS}

The following values were measured: 3 pressures of hydraulic oil in the system: output from the hydro generator, pressure on the piston $\mathrm{p} 1$ and on the piston rod p2 (annulus), from which were derived theoretical forces in the axis of piston rod. The next step was firstly analysis of the stationary and passive resistance (friction) in the rolling bearings, friction between gate and water and forces on arrest. Secondly it was analysis of dynamical forces needed for the run of the gate and water before the gate. 


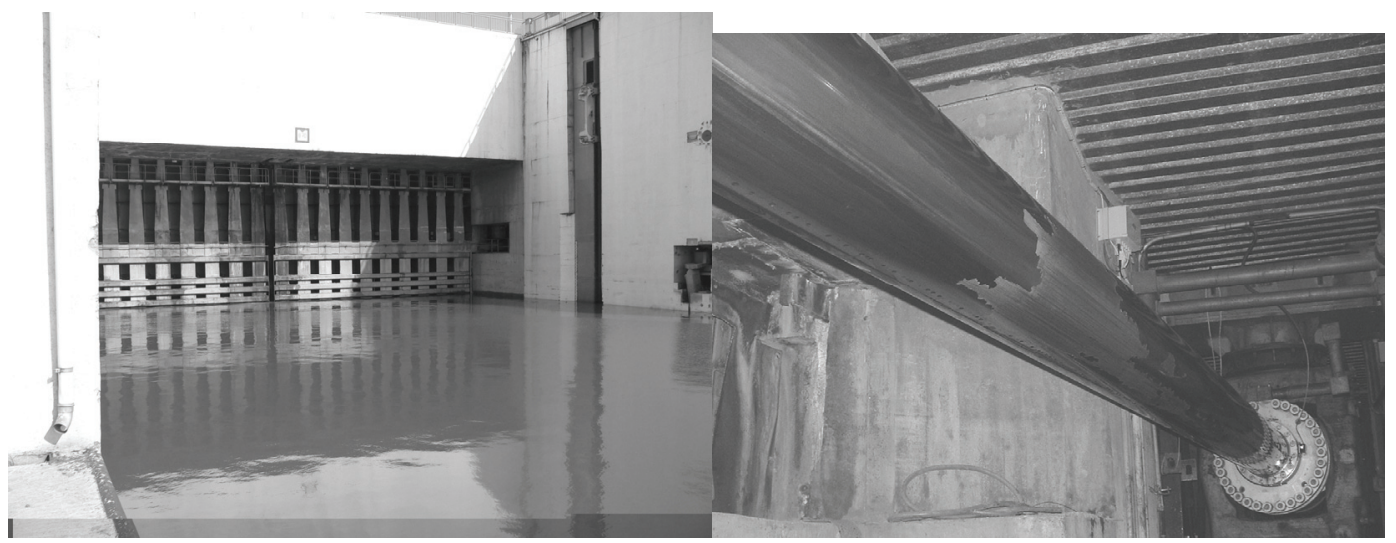

Fig.1: The view on the lower gate locks and driving hydraulic motor

For the purposes of digital filtration, a slipper diameter with span of 101 samples was used. The measurement was left running continuously for app. 17 hours and was interrupted after a technical fault in the left chamber. The principle of the experiment was based on the fact, that it was manipulated with the gates (closed and open) firstly in the dry dock and then again after each submersion of the dock by a $1 \mathrm{~m}$ high water level. This process was repeated by the fact, that the manipulation of the gates was done under two different velocities- normal velocity (dropped with the interval 10, 2 hydraulic aggregates), and half of the normal velocity (1 aggregate)

From the measured values:

- $\quad$ The pressure peaks during gate stopping never exceeded $16 \mathrm{MPa}$, maximum pressure on the piston rod during manipulation with constant velocity does not exceed $4.5 \mathrm{MPa}$ for 1 $\mathrm{HG}$ and $6.5 \mathrm{MPa}$ for $2 \mathrm{HG}$

- The maximum pressure on the piston side during the manipulation with constant velocity, does not exceed the value $3.5 \mathrm{MPa}$ for $1 \mathrm{HG}$ and 5.5 MPa for $2 \mathrm{HG}$

- The pressure measurement differs significantly, depending on the lower water level in the pre-determined position area- caused by hand- manipulation

- The gate motion with the constant velocity was secured by a relatively small force, approximately $11,7.10^{4} \mathrm{~N}$, this value was not dependent on the height of the lower water level

- $\quad$ The arrest pressures to the wall of the chamber was too high- up to $323.10^{4} \mathrm{~N}$ !

- The pressure peaks for running up the gate from the wall reached the value for the maximum lower water level up to $105.10^{4} \mathrm{~N}$. These values could be eliminated by appropriate $\mathrm{P}-\mathrm{Q}$ regulation of sources of pressure energy.

\section{THE COMPUTATION OF FORCES ACTING ON THE PISTON OF HORIZONTALLY ORIENTED HYDRAULIC CYLINDER:}

Active areas:

$S_{1}=\frac{\pi \cdot d_{1}^{2}}{4}, \quad S_{2}=\frac{\pi \cdot\left(d_{1}^{2}-d_{2}^{2}\right)}{4}$

where

$d_{1} \quad$ diameter of the piston

$d_{2} \quad$ diameter of the piston rod 
$S_{1}$

$S_{2}$ areas of the piston area of the annulus

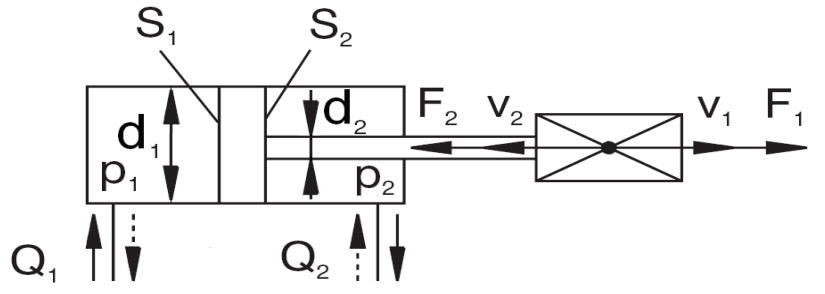

Fig.2: The description of direct hydro motion

\section{LOADING OF HYDRAULIC CYLINDER BY AXIAL AND PRESSURE FORCES}

The horizontally situated hydraulic cylinders force not only acts in the horizontal axis but also the vertical axis. This type of loading is determined as buckling with bending.

The deflection in equilibrium state of loaded bar is characterized as:

$y(x)=y_{0}(x)+y_{\mathrm{F}}(x)$,

where

$y_{0}(x) \quad$ deflection from bending moment caused by lateral loading,

$y_{\mathrm{F}}(x) \quad$ deflection from bending moment caused by pressure force,

the bending moment is defined as:

$M(x)=M_{0}(x)+M_{\mathrm{F}}(x)=M_{0}(x)+F \cdot y(x)$.

where

$M_{0}(x) \quad$ bending moment from lateral loading,

$M_{\mathrm{F}}(x) \quad$ bending moment from pressure force,

$F \quad$ force from the pressure of operating fluid.

The strength condition is as follows:

$\left|\sigma_{\max }\right|=\frac{M_{\max }}{W_{y}}+\frac{F}{S_{2}} \leq \sigma_{\text {dov }}$,

(4)

where $W_{y}$ is module of intersection while bending.

Differential equation of deflection curve:

$y^{\prime \prime}(x)=-\frac{M(x)}{E \cdot J}=-\frac{1}{E \cdot J} \cdot\left[M_{0}(x)+F \cdot y(x)\right]$.

Equation (5) could be modified by substitution:

$p^{2}=\frac{F}{E \cdot J}$,

To the following form:

$y^{\prime \prime}(x)+p^{2} \cdot y(x)=-\frac{p^{2}}{F} \cdot M_{0}(x)$.

(7)

General solution of equation (8) is

$y(x)=A_{\mathrm{w}} \cdot \cos p x+B_{\mathrm{w}} \cdot \sin p x+y_{\mathrm{p}}(x)$, 
where

$A_{\mathrm{w}}, B_{\mathrm{w}} \quad$ integrative constants,

$y_{\mathrm{p}} \quad$ particular solution of the complete differential equation.

According to the evaluation of the deflection curve (8) we could by use of (3) determine the bending moments as a function of length and undergo strength computation under condition (4).

\section{THE COMPUTATION OF STRESSES ON THE CYLINDER WALL DUE TO FLUID PRESSURE}

Cylindrical containers substituting the inner or outer loading are, in terms of strength and elasticity, considered as thick-walled. And is true if the radius of the wall cylinder thickness to the inner radius is larger than 0,1 . The greatest stress occurs on the inner circuits of the containers, because of these, it is necessary to determine the reduced stress during the strength control.

$$
\sigma_{\text {red }}\left(\mathrm{r}_{1}\right)=\sigma_{1}-\sigma_{2}=\sigma_{\mathrm{kt}}\left(\mathrm{r}_{1}\right)-\sigma_{\mathrm{r}}\left(\mathrm{r}_{1}\right)=\sigma_{\mathrm{kt}}\left(\mathrm{r}_{1}\right)+p_{1}
$$

The stress condition is as follows:

$$
\begin{aligned}
& \sigma_{\mathrm{dov}} \geq \sigma_{\mathrm{red}}, \\
& \sigma_{\mathrm{dov}} \geq \sigma_{\mathrm{kt}}\left(\mathrm{r}_{1}\right)+p_{1}, \\
& \sigma_{\mathrm{dov}}=\frac{k_{2} \cdot \sigma_{\mathrm{kt}}}{k_{1}}, \text { where }
\end{aligned}
$$

$k_{1} \quad$ security coefficient for hydraulic parts,

$k_{2} \quad$ security coefficient for dynamically loaded parts,

$\sigma_{\mathrm{kt}} \quad$ critical stress,

$\sigma_{\text {dov }} \quad$ allowed stress,

$\sigma_{\text {red }} \quad$ reduced stress.

$\sigma_{\mathrm{r}}=\frac{p_{1} \cdot r_{1}{ }^{2}-p_{2} \cdot r_{2}^{2}}{r_{2}{ }^{2}-r_{1}{ }^{2}}-\frac{\left(p_{1}-p_{2}\right) \cdot r_{1}^{2} \cdot r_{2}{ }^{2}}{\left(r_{2}{ }^{2}-r_{1}{ }^{2}\right) \cdot r^{2}}$

$\sigma_{\mathrm{t}}=\frac{p_{1} \cdot r_{1}^{2}-p_{2} \cdot r_{2}^{2}}{r_{2}^{2}-r_{1}^{2}}-\frac{\left(p_{1}-p_{2}\right) \cdot r_{1}^{2} \cdot r_{2}^{2}}{\left(r_{2}^{2}-r_{1}^{2}\right) \cdot r^{2}}$

Simplifying, we assume: $p_{2}=0$.

For $r=r_{1}$ is valid:

$$
\sigma_{\mathrm{t}}\left(r_{1}\right)=\frac{p_{1} \cdot\left(r_{1}^{2}+r_{2}^{2}\right)}{r_{2}^{2}-r_{1}^{2}},
$$




$$
\sigma_{\mathrm{dov}} \geq \frac{p_{1} \cdot\left(r_{1}^{2}+r_{2}^{2}\right)}{r_{2}^{2}-r_{1}^{2}}+p_{1}
$$

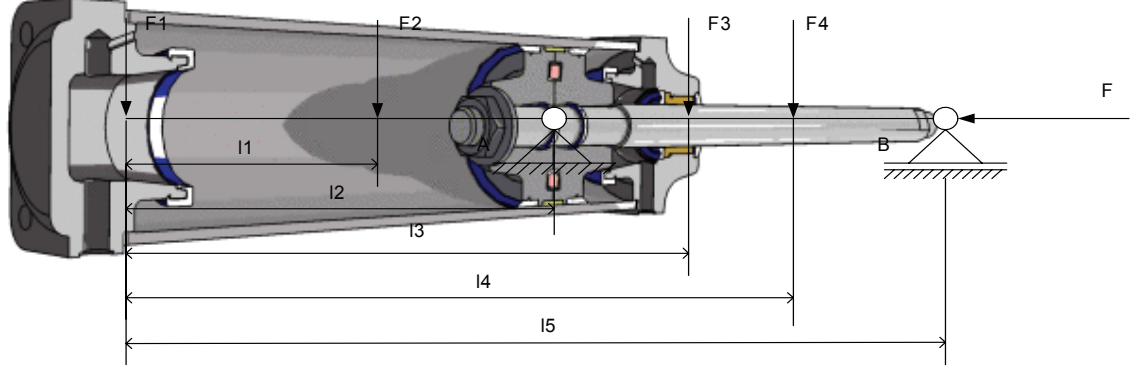

Fig.3: Forces acting on the cylinder and its application points (length dimensions)

Application for the concrete hydro motor :

Length dimensions

$$
\begin{aligned}
& l_{1}=3.395 \mathrm{~m} \\
& l_{2}=6.375 \mathrm{~m} \\
& l_{3}=6.975 \mathrm{~m} \\
& l_{4}=11.032 \mathrm{~m} \\
& l_{5}=14.800 \mathrm{~m}
\end{aligned}
$$

The equilibrium of lateral, axial moments and torque:

$$
\begin{array}{ll}
\sum_{\mathrm{i}=1}^{\mathrm{n}}\left(F_{\mathrm{i}}\right)_{\mathrm{y}}=0 ; & R_{\mathrm{A}}+R_{\mathrm{B}}-F_{1}-F_{2}-F_{3}-F_{4}=0 \\
\sum_{\mathrm{i}=1}^{\mathrm{n}}\left(\mathrm{F}_{\mathrm{i}}\right)_{x}=0 ; & F=F^{*}, \\
\sum_{\mathrm{i}=1}^{\mathrm{n}}\left(\mathrm{M}_{\mathrm{i}}\right)_{z}=0 ; & -F_{1} \cdot l_{5}-F_{2} \cdot\left(l_{5}-l_{1}\right)-F_{3} \cdot\left(l_{5}-l_{3}\right)-F_{4} \cdot\left(l_{5}-l_{4}\right)+R_{\mathrm{A}} \cdot\left(l_{5}-l_{2}\right)=0 .
\end{array}
$$

Reaction $R_{\mathrm{A}}, R_{\mathrm{B}}$ :

$$
\begin{aligned}
& R_{\mathrm{A}}=\frac{1}{\left(l_{5}-l_{2}\right)} \cdot\left(F_{1} \cdot l_{5}+F_{2} \cdot\left(l_{5}-l_{1}\right)+F_{3} \cdot\left(l_{5}-l_{3}\right)+F_{4} \cdot\left(l_{5}-l_{4}\right)\right) \\
& R_{\mathrm{B}}=F_{1}+F_{2}+F_{3}+F_{4}-R_{\mathrm{A}}
\end{aligned}
$$

The equation of bending moments and deflection curves:

$l_{3} \leq x_{4} \leq l_{4}$

$M_{\mathrm{O}(\mathrm{x} 4)}=-F_{1} \cdot x_{4}-F_{2} \cdot\left(x_{4}-l_{1}\right)-F_{3} \cdot\left(x_{4}-l_{3}\right)+R_{\mathrm{A}} \cdot\left(x_{4}-l_{2}\right)$

$y_{(\mathrm{x} 4)}^{\prime}=-\frac{1}{E \cdot J_{2}} \cdot\left(-F_{1} \cdot \frac{x_{4}^{2}}{2}-F_{2} \cdot\left(\frac{x_{4}^{2}}{2}-l_{1} \cdot x_{4}\right)-F_{3} \cdot\left(\frac{x_{4}^{2}}{2}-l_{3} \cdot x_{4}\right)+R_{\mathrm{A}} \cdot\left(\frac{x_{4}^{2}}{2}-l_{2} \cdot x_{4}\right)\right)+C_{4}$ 
$\mathrm{y}_{(\mathrm{x} 4)}=-\frac{1}{E \cdot J_{2}} \cdot\left(-F_{1} \cdot \frac{x_{4}^{3}}{6}-F_{2} \cdot\left(\frac{x_{4}^{3}}{6}-l_{1} \cdot \frac{x_{4}^{2}}{2}\right)-F_{3} \cdot\left(\frac{x_{4}^{3}}{6}-l_{3} \cdot \frac{x_{4}^{2}}{2}\right)+R_{\mathrm{A}} \cdot\left(\frac{x_{4}^{3}}{6}-l_{2} \cdot \frac{x_{4}{ }^{2}}{2}\right)\right)+C_{4} \cdot x_{4}+D_{4}$

$l_{4} \leq x_{5} \leq l_{5}$

$M_{\mathrm{O}(\mathrm{x} 5)}=-F_{1} \cdot x_{5}-F_{2} \cdot\left(x_{5}-l_{1}\right)-F_{3} \cdot\left(x_{5}-l_{3}\right)-F_{4} \cdot\left(x_{5}-l_{4}\right)+R_{\mathrm{A}} \cdot\left(x_{5}-l_{2}\right)$

$y_{(\mathrm{x} 5)}^{\prime}=-\frac{1}{E \cdot J_{2}} \cdot\left(-F_{1} \cdot \frac{x_{5}^{2}}{2}-F_{2} \cdot\left(\frac{x_{5}^{2}}{2}-l_{1} \cdot x_{5}\right)-F_{3} \cdot\left(\frac{x_{5}^{2}}{2}-l_{3} \cdot x_{5}\right)-F_{4} \cdot\left(\frac{x_{5}^{2}}{2}-l_{4} \cdot x_{5}\right)+R_{\mathrm{A}} \cdot\left(\frac{x_{5}^{2}}{2}-l_{2} \cdot x_{5}\right)\right)+C_{5}$

$y_{(x 5)}=-\frac{1}{E \cdot J_{2}} \cdot\left(-F_{1} \cdot \frac{x_{5}^{3}}{6}-F_{2} \cdot\left(\frac{x_{5}^{3}}{6}-l_{1} \cdot \frac{x_{5}^{2}}{2}\right)-F_{3} \cdot\left(\frac{x_{5}^{3}}{6}-l_{3} \cdot \frac{x_{5}^{2}}{2}\right)-F_{4} \cdot\left(\frac{x_{5}^{3}}{6}-l_{4} \cdot \frac{x_{5}^{2}}{2}\right)+R_{\mathrm{A}} \cdot\left(\frac{x_{5}^{3}}{6}-l_{2} \cdot \frac{x_{5}^{2}}{2}\right)\right)+C_{5} \cdot x_{5}+D_{5}$

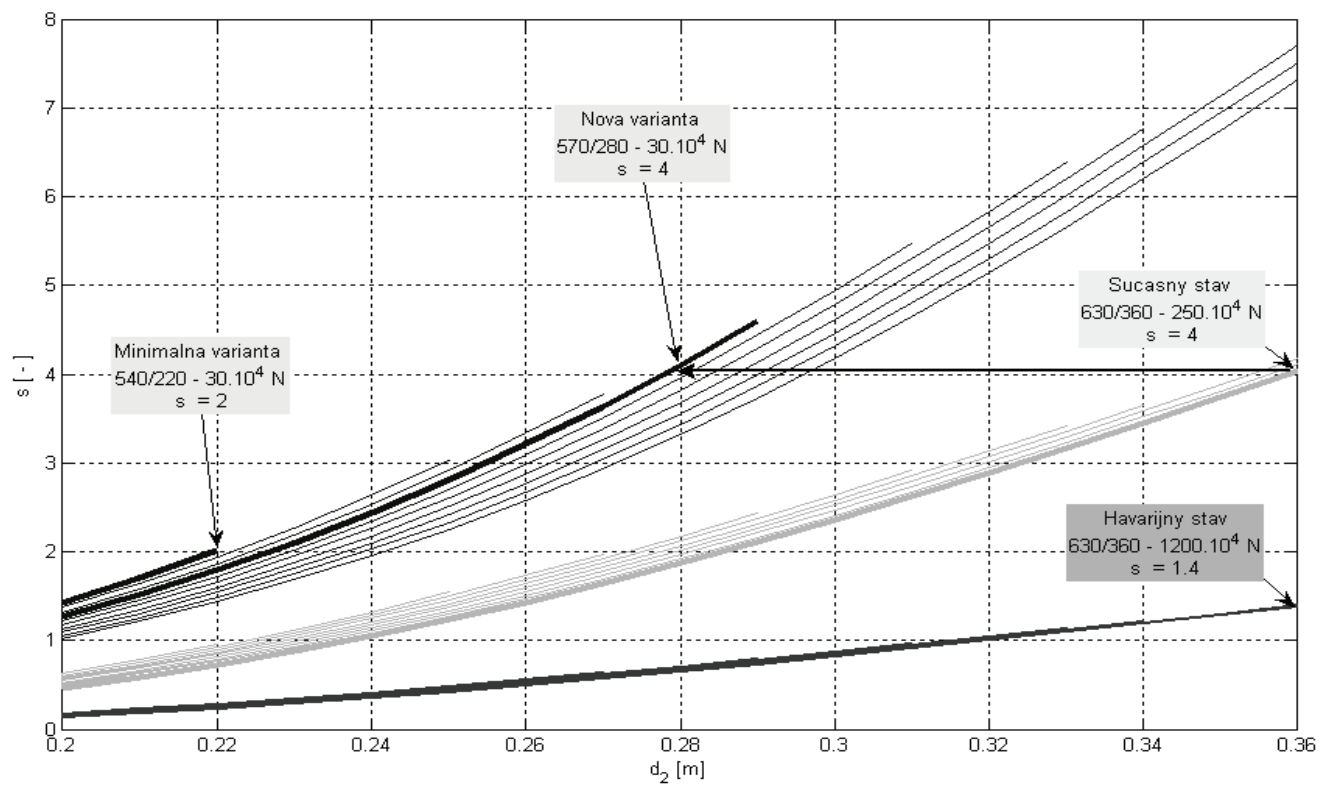

Fig.4: The curves of security, depending on the diameter of the piston, piston rod and the buckling force

The graphical output from the program "Kontrola hydraulického valca.m" is shown in figure 4. The figure shows the rates characterizing the dependence of security from the diameter of the piston rod $d_{2}$ and the parameter of its own system of curves is the diameter of piston $d_{1}$ ranging from $630-540 \mathrm{~mm}$ by 3 different loadings. In the upper part of the graph the curves for the buckling force $30.10^{4} \mathrm{~N}$ are marked, in the middle for buckling force $250.10^{4} \mathrm{~N}$ and the lower curve express the curves for the emergency situation/operation, represented by the buckling force $1200.10^{4} \mathrm{~N}$. By lowering the demanded buckling force, it is possible to decrease the dimensions of the hydraulic cylinder, by the same value of security, to the values 570/280. The minimum acceptable possibility is the hydraulic cylinder with the dimensions 540/220 with a security $s=2$.

Note: In the case of the supposed emergency operation, the security $s=1,4$ for the hydraulic cylinder 630/360 was computed. 


\section{CONCLUSIONS}

Within the analysis of the experiments performed on the hydraulic drive system of lower gate, in the sense of modernizing the hydrostatic drive system of lower gate locks at the waterworks Gabčíkovo, the forces acting on the horizantally stored hydraulic cylinders was computed. From the alternative computations it follows, that except from the actual size of hydraulic cylinders $\Phi 630 / \Phi 360-6550$ with a security of $s=4$ under the load $250.10^{4} \mathrm{~N}$ and security $s=1,4$ under the load $1200.10^{4} \mathrm{~N}$ (emergency mode), the possibilities for the dimensions of the hydraulic cylinder were offered, $\Phi 570 / \Phi 280-6550$ with a security of $s=4$ and $\Phi 540 / \Phi 220$ - 6550 with a security $s=2$. Nowadays we do not assume the emergency mode of the lower gates, it was found out, that the driving hydro motors could be significantly relieved (from app. actual 40tons) and by this step it is possible to significantly increase its safety and lifetime.

\section{LITERATURE}

[1] KRCHNÁR, J.: Experimentálna identifikácia hydrostatického pohonu. Bratislava. 1989. Kandidátska dizertačná práca.

[2] TREBUŇA, F., ŠIMČÁK F., JURICA, V.: Pružnost' a pevnost'. ELFA Košice 2005.

[3] STRAČÁR, K. a kol.: Hat'ová prevádzka a suchý dok plavebnej komory VD Gabčikovo, STU Bratislava, Strojnícka fakulta, Bratislava, 2000. Výskumná správa. 